\title{
Tubule density at different sample sites around the Stratum medium of horse hoof horn
}

\author{
L. Hopegood, D. Abraham and C. Shervey \\ The Nottingham Trent University, School of Land-based Studies, Brackenhurst, Southwell, Notts, NG25 OQF, Email: \\ lyn.hopegood@ntu.ac.uk
}

Introduction Microscopic analysis shows that equine hoof wall is composed of distinct phases of tubular and intertubular horn. The tubule density (TD) of hoof horn is found by ascertaining the number of tubules per unit area and is believed to relate to mechanical properties, resistance to wear, "quality", hardness and moisture content. The straight grid previously used to ascertain the TD of hoof horn may omit certain tubules on both the inner and outer hoof wall as the wall itself is curved. This present study examined whether there was a significant difference in results for TD between using the conventional straight grid method and a novel method using a curved grid. TD was also compared across three sample sites. An analysis of TD from four equal sections (zones) across the hoof wall was also carried out.

Materials and methods The left fore feet of 10 randomly selected slaughterhouse horses and ponies were used to provide hoof samples. Study 1 - Hoof sections were cut on a microtome from the midline dead centre (MDC) of the Stratum medium, were stained with Haematoxylin and Eosin and mounted on $35 \mathrm{~mm}$ slides and projected onto a screen. Curved grids were constructed for individual samples based on the curve of the outer Stratum medium. The chosen grid was placed over the projected image. A tubule count provided the Initial Tubule Density. A conversion was then applied to determine actual tubule density. Study 2 - Samples were removed from the Stratum medium of the hoof wall at 3 sample sites: the MDC, medial and lateral sites. The method used in Study 1 to ascertain TD was also used for this study but the same straight grid was used for all samples.

Results Study 1 There was no significant difference between the mean TD for the full hoof wall depth for samples analysed using the straight grid (18 tubules $\mathrm{mm}^{-2}$ ) and those analysed using the curved grid (19 tubules $\left.\mathrm{mm}^{-2}\right)$ (Mann Whitney $U$ test, $\mathrm{p}>0.05$ ). However, the pattern of tubule distribution did not relate to the stepwise distribution described by previous authors for pony and horse hoof horn (Reilly et al. 1996; 1998) but did appear to be similar to that previously shown for donkey hoof horn by Hopegood (2002). However conflicting results may be due to samples being used from both horse and pony hoof horn. Study 2 - The median tubule densities at the different sample sites were 6, 10 and 10 tubules $\mathrm{mm}^{-2}$ for medial, MDC and lateral samples respectively and are shown in Figure 1 . There were significant differences in TD between the 3 sample sites (Kruskal-Wallis test, $\mathrm{p}<0.05$ ). The TD for the medial site was significantly lower than either for midline or lateral samples (Mann Whitney $U$ test, $\mathrm{p}<0.05$ ). There was also a significant difference between TD for zonal comparisons between the three sample sites (Mann Whitney $U$ test, $\mathrm{p}<0.05$ ). The TD at different sample sites around the hoof wall capsule had previously not been ascertained.

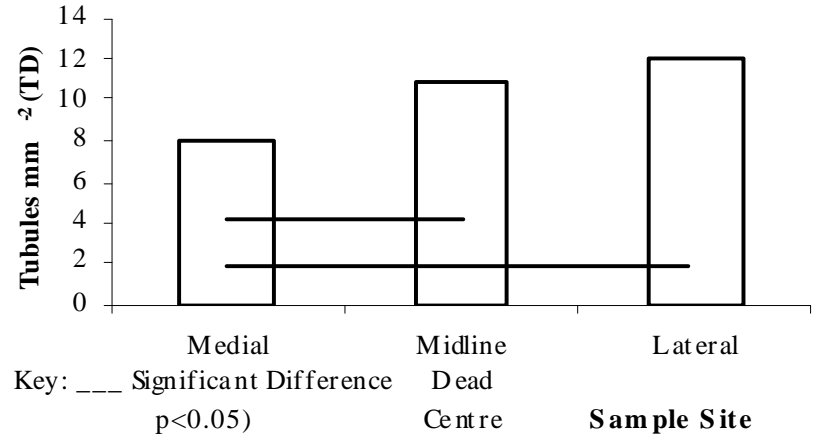

Figure 1 - Tubule Density at Different Sample Sites Around the Hoof Wall
Conclusions A straight or curved grid may be used to ascertain the TD of horse hoof horn. Studies on the TD of hoof horn should take into account the sampling site as TD varies according to sample position. As TD is believed to relate to the mechanical properties of the hoof, the establishment of a significantly lower TD for the medial sample site when compared to the other sites may reflect differences in the mechanical and functional properties of horse hoof horn in these different areas. Indeed, the medial wall of the hoof is often found to be more upright than the lateral wall. The TD may then be a reflection of the weight bearing capacity of the medial aspect of the wall.

\section{References}

Hopegood, L. (2002) Tubule Density, Moisture Content and Mechanical Properties of Donkey Hoof Horn. PhD Thesis, De Montfort University.

Reilly, J.D., Cottrell, D.F., Martin, R.J. and Cuddeford, D. (1996) Tubule density in equine hoof horn. Biomimetics 4:1, 23-35. 
Reilly, J.D., Collins, S.N., Cope, B.C., Hopegood, L. and Latham, R.J. (1998) Tubule density of the Stratum medium of horse hoof. Equine vet. J., Suppl. 26, 4-9. 